\title{
Integrative principles and criteria for implementation of faecal sludge management in Russian Federation
}

\author{
Alena Basamykina*, Ekaterina Kurkina, Maria Kameristaya, and Valeria Zelenina \\ Peoples Friendship University of Russia (RUDN University), Faculty of Ecology, 6 Miklukho- \\ Maklaya Street, Moscow, 117198, Russian Federation
}

\begin{abstract}
Faecal sludge management (FSM) is an organized program that allows regularly to collect, transport, process and utilize faecal sludge as biological waste. A faecal sludge management in settlements in Russian Federation is so bad organized or only partially exist. There are significant gaps as well as general understanding of institutional roles and responsibilities at national, state and city levels. Planning should be done in a temporal and spatial context. Cities, while maintaining short-term stability, will be guided by the goals of a long-term vision of creation. Planning system of faecal sludge management in Russian Federation that involves these blocks: regulatory framework, selection of best available techniques (BAT), financing and planning mechanisms, is analyzed. Integrated approach to the creation and regulation of a faecal waste management are shown. For implementation such approach, a system of evaluation criteria is required in order to determine the end product and, accordingly, determine development direction of this industry in the geographical area where this system will operate.
\end{abstract}

\section{Introduction}

Presently, the problem of the generation and management of various waste types is very acute all over the world. However, if the problem of the inorganic waste generation can be partially solved by banning the manufacture of certain products types, then the problem of the organic waste generation, including faecal sludge, is much more difficult to solve. The most acute socio-economic and environmental problem is the problem of faecal sludge management. Faecal sludge accumulates in pit latrines and septic tanks located in private households, as well as in public toilets, hotels, etc. Despite the high degree of urban settlements development, and, consequently, the development of sewerage networks, faecal sludge management is still poorly functioning or completely absent in many regions of the world, including the Russian Federation.

There are about 20,000 rural settlements and almost 200 urban-type settlements with more than 10,000 people in Russian Federation [1]. Faecal sludge management in these settlements is so bad organized or only partially exist. There are significant gaps as well as general

* Corresponding author: alena.basamykina@gmail.com 
understanding of institutional roles and responsibilities at national, state and city levels. There is no consistency $[2,3]$.

Specifically, waste accumulation, collection or removal, and transportation stages may function well, but the stages of processing and utilization may be absent at all. Commonly, there is no faecal sludge processing line (including co-processing with wastewater at sewage treatment plant), due to insufficient funding $[3,4]$. In addition, there is a lack of awareness of the existence of FSM, as well as its associated benefits and the inherent links of its poor condition to public health [4].

To solve the problem of processing and utilization of faecal sludge, it is necessary not only to modernize the already existing obsolete one, but to create a fundamentally new one, which must be adapted to specific environmental factors, such as humidity, temperature, land topography, the prevailing microorganisms biocenosis and ongoing biochemical processes $[5,6,7]$. Such system should also be focused on the use of innovative technologies and, first of all, faecal sludge processing technologies and recovery of energy potential from them $[6,8]$. Thus, it becomes possible to process faecal sludge into a useful resource that can be reused. That's an important basis for a circular economy [5,9].

Faecal sludge management is an organized program that allows regularly to collect, transport, process and utilize this type of biological waste. Such systems are being improved through changes in local government regulations and through marketing campaigns that increase participation and willingness to pay for services rendered [10-12].

The development of principles and criteria for a step-by-step planning strategy for FSM was based on the market approach [5,6,13-16], which involves planning "accumulation collection - transportation - processing - utilization" chain.

For system stability, it is necessary to structure the favorable environment in six categories [17]:

1) government support;

2) the regulatory framework;

3) institutional arrangements;

4) skilled staff and the required capacity;

5) financial mechanisms;

6) socio-cultural understanding and education.

The above categories can be combined into the following three system components (Fig. 1), which, as a result of co-implementation, will help to achieve the maximum potential for changes in this area [10]:

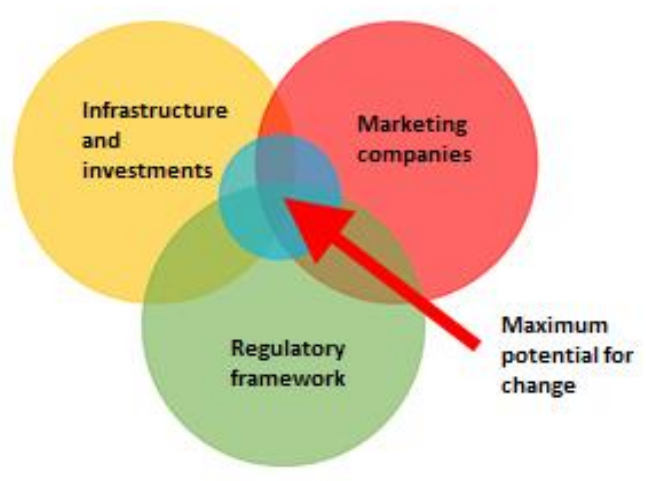

Figure 1. Components of a faecal waste management [10]

Regulatory framework is an enabling environment that includes training, access to funding, and political aspects such as local ordinance on faecal sludge management. 
Marketing companies are companies that inform people about the program and increase their motivation to comply with and pay for the service.

Infrastructure and investments are technological equipment, including vacuum sewage trucks and the use of best available techniques (BAT) for faecal sludge treatment, as well as pit latrine replacement with septic tanks and improvement in the design of local septic tanks.

Many past water supply and sanitation projects have failed due to the lack of an integrated approach. Sanitation programs need to take into account the above aspects to ensure the longterm sustainability of the sanitation infrastructure. Such programs should also include not only approaches to the design of sanitary control systems in accordance with local requirements, but also include business models that involve management method, method of occupation and operation of such systems [17-19].

Implementation of sustainable FSM is also an important step towards achieving sustainable development goals. Such system should include three important components: planning (creating a step-by-step management of faecal sludge from source to end product), management (integrated and local control at each stage of circulation, as well as transportation control) and technology (selection is made taking into account the characteristics of accumulation places, economic funds, the end product, etc.) [20]. Considering these components as a complex, and not separately, it is possible to achieve three main goals. It is necessary to create a management system for waste of decentralized sewage for these goals: public health, environmental protection, and possibility of generation secondary resources.

Given the certain limitations of municipal management (organizational, legal, financial, as well as problems related to the peculiarities of each city or settlement), step-by-step planning and development of strategy for safe and sustainable sanitary control systems is necessary. Planning should be done in a temporal and spatial context. Under such conditions, cities, while maintaining short-term stability, will be guided by the goals of a long-term vision of creation $[7,13]$. Thus, design of system involves following stages or blocks.

\section{Main blocks of faecal sludge management}

\subsection{First block: Regulatory framework}

Presently, there is no unified regulatory framework in Russian Federation in the field of sustainable faecal sludge management, therefore, implementation of flow control at all stages is difficult. It is necessary in each individual region and municipality (taking into account the existing planning strategy) to determine the rules and norms for handling this type of biological waste, as well as to clarify land management standards and rules regarding construction and operation, processing and utilization. It is worth noting, that in some cases the installation of reception stations and facilities for faecal sludge treatment in residential areas is prohibited [2,21]. The faecal sludge management activities should not run counter to the rules for handling production and consumption waste (do not contradict Federal Law No. 89 "Production and consumption waste" [22]).

In addition, there are no standards for the design of systems for the faecal sludge accumulation and their use, which allow adequate sludge accumulation of, as well as general rules for emptying of filling system. It is necessary to establish design standards for toilets (both for pit latrines and septic tanks), which would allow for proper containment and facilitate emptying [4].

It is also necessary to take into account the environmental legislation related to recycling and reuse of faecal sludge and to impact on the environment, as well as laws in the agricultural field for re-using potential of processing products of faecal sludge. Consideration 
should be given to regulation of secondary resources in agriculture (for example, certificate of quality, reuse restrictions, maximum permissible concentrations) [2,21].

For example, one of essential aspects is introduction of this type of waste into the FCCO $[23,24]$. Due to the peculiarities of accumulation, faecal waste from pit latrine and from septic tank has very different elemental, phase and microbiological composition. Faecal sludge from pit latrine has a higher content of pollutants than "water" from septic tank, which has higher content of incoming and outgoing domestic wastewater, as well as less municipal solid waste $[14,19,25]$. There is faecal sludge in the Federal waste classification catalog (FCCO), but there is only as "waste (sludge) from pit latrines" (7 3210001304 ), while faecal sludge also accumulates in the septic tank (septage). There are also "faecal waste from decentralized sewage systems" (7 3210000000$)$ and "waste of cleaning toilet cabins, dry closets, chemical toilets" ((7 322000000 0), but they also do not reflect the special characteristics of septage [24]. It is necessary to divide this waste into two types: faecal sludge from pit latrines and faecal sludge from septic tanks.

We should also principally eliminate feacal sludge as waste, since it is a resource that must be used. At the same time, if we produce a certain product from faecal sludge, it is necessary to approve and register it before selling it (in case this product is not used for the processor's own needs).

\subsection{Second block: Selection of best available techniques (BAT)}

Selection of BAT for faecal sludge treatment and utilization will depend on environmental conditions, similarly the market demand for end product in the region and regional environmental-economic policies. FSM (collection, storage, transportation, treatment, and reuse of end product) is determined by technology of their end disposal in the region: selection of a preliminary processing line depends on it $[9,20]$.

The correct selection of BAT is necessary for more reliable operation and maintenance of the system at all stages in the "accumulation - collection - transportation - processing disposal/reuse of secondary resources" chain. When planning the process flowchart, it is significant to consider technologies for environment protection from the effects of technological processes (e.g., filtrate treatment during dewatering) and additional procedures to improve the quality of the final product (e.g., biogas treatment) $[25,26]$.

Cities should consider lead-time interval of existing sanitary control systems, including processes, technologies, and infrastructure, and should explore the possibilities of integrating the planned system into the existing including management [2,13]. Based on the planning results, it is necessary to decide whether the existing infrastructure needs to be replaced, restored, upgraded, or used in its current state as part of the proposed system [27].

One alternative to solve this problem of irrational flows is to install faecal sludge pumping stations close to densely populated areas. It will create a two-step process for faecal sludge handling. Local operators (main transport) can safely unload faecal sludge to the transfer station for temporary storage. When storage tank is full, a large vacuum truck transports it (secondary transport) to a regulated disposal place or wastewater treatment facilities [28].

It is possible to add sludge dewatering before long-distance transportation, which will increase efficiency of system and reduce costs [26,28]. Licensing, record keeping, and reporting, monitoring of service providers related to the collection, transportation, and treatment of faecal sludge are necessary [2].

Significant criteria for BAT selection will be resistance to changes in weather conditions, land capacity, the possibility of co-disposal with other organic waste, identification of process by-products, time and process automation, energy consumption, waste production, capital expenditures, operating costs, transportation costs from source to buyer, process efficiency. 
The economic benefit of the end faecal sludge products can potentially increase the stability of control system, have been offsetting part of processing and disposal costs. However, local context and markets need to be taken into account, as the potential market value of the same end products varies considerably from country to country. It was a testament to the importance of market attractiveness as one of the most important criteria for selecting resource recovery technologies. This factor has to be taken into account together with many other problems that need to be solved to produce acceptable end products from faecal sludge $[9,14]$.

\subsection{Third block: Financing and planning mechanisms}

Major limitations in the way of the establishment of FSM lie in the institutions and policies of countries. The public sector is often weak in terms of knowledge, structures, planning capacity, and bureaucratic procedures, and mechanisms do not always exist to recover investment costs, operation, or management, leading to a deterioration in services delivery or even the abandonment of the system [17,29].

It is essential to understand that sustainable FSM have a service-oriented approach. Infrastructure and technology are part of such approach, but can only be effective if there is a customer focus. Such improvements typically include easy access to service providers, faster response times, fewer quantity failures, access to hard-to-reach facilities, and more reliable operations. In general, the private sector is better at achieving this than the government sector because it has flexibility and the ability to innovate $[5,9]$.

It is important to note that, often due to the high sanitary tax, residents empty the places of accumulation on their own, so unprocessed faecal sludge enters the environment, not ensuring its protection and protection of human health. A possible solution would be to add a fee to the water bill or property tax or create a similar collection mechanism to help finance it as the program. People tend to find this a much more affordable option than paying for septic tanks emptying. It also attracts the performers of this phase because they achieve cost recovery after about 4,5 years. The levy can then be accustomed to expand services, fund the upgrading of septic tanks for the socially disadvantaged, or benefit if the private sector manages this program. [2,10,18,25].

For example, in Kenya, service tariffs include fees charged for discharging to existing wastewater treatment plants, but taking into account additional factors such as short distances for trucks and affordability for low-income customers [30]. There is other system in Tanum, Sweden. The municipality is responsible for emptying, storing and reusing faecal sludge and contracts with farmers or entrepreneurs. Where the technical committee is responsible for sewer pipes and septic tanks, the municipality organizes collection and re-use on arable land in accordance with signed agreements. Besides, owners can also make an individual contract with an approved entrepreneur or farmer who collects faecal sludge for processing and utilization. The fee is indicated in the contract. Urine can be processed and used. [31].

Regular or planned emptying is an alternative system tested in various locations, including Indonesia, Malaysia, and the Philippines [9,27,32]. But it is necessary to understand that such a system requires a high degree of organization and communication with customers, easy access to septic tanks, and an extensive database of local objects. The problem with such system is that even if people regularly pay for emptying, they do not necessarily use these services.

Since transportation is the largest part of the cost of faecal sludge management, traditional companies that empty facilities in the immediate vicinity but often do not deliver it for treatment are usually cheaper for the operator and sometimes also for the owner. It is therefore essential to offer improved services with prices available to users. The affordable 
price involves the BAT use and proper maintenance. It is also necessary to establish viable financial mechanisms to ensure sustainable services at an affordable price. [9,27]

One of the planning problems is the complete lack of funding and banking channels to implement the project [3]. In such a case, partnerships among actors could lead to the more rapid development of faecal sludge management in a region or area. Many partners, including local authorities, would be very interested in investing in the project once the sanitation plan is in place. [16,33].

The responsibilities for sanitation services are divided among departments, ministries, and organizations and only sometimes overlap very often. It complicates coordinated action that can lead to conflict between stakeholders over resources and sphere of influence [17,29].

Firstly, stakeholders must be identified at the municipal level to assess their interests. Stakeholders should identify at the municipal, regional, and state levels. They are defined by three significant organizational sectors: private, public, and non-governmental (commercial). Secondly, a thorough analysis of information resources and reports is necessary to determine the role and level of potential participation of each party in the implementation and operation of the system in the first place, as well as their positive or negative impact on the project $[2,15,21,27]$. Interested parties are both faecal sludge producers (private homeowners, urban private companies) and buyers of products (farms, private production companies). It is also necessary to identify stakeholders in the intermediate stages of the chain, for example, companies that provide sanitation services and transportation of faecal sludge to the treatment site or utilization $[9,34]$.

The mechanism of public-private partnership may become a variant of the cooperation where as a result a private company could be able to generate their proceeds from the project by providing value-added services and/or the use of different solutions that reduce the cost at design, building or operation stage [35]. It is possible to use private capital based on the cost of recovered resources. It will also contribute to reduce waste and reuse products and waste. In a postmodern sanitation system with combined financing, both users and buyers of reuse products will benefit when there is demand, allowing for more reliable operation and maintenance of the system at all stages [8].

One way solution of this problem may be a subsidy or a tax relief, user fees, and revenues from the sale of end product, or a combination of all these options. It will help to reduce capital expenditures for purchase of collecting and transportation equipment, and also minimize transportation distant and number of emptying routes. Nevertheless, the demand for the product will be of key importance. It is necessary to assess potential income from end product sales $[18,19,21,25]$. Faecal sludge management should be regulated talking into account waste market interest because the main part of system will generate of priority end product. Moreover, system should fit into the regional territorial waste management strategy. It is necessary to provide more detailed analysis of market demand at municipal and regional levels. Planning should be carrying at the project stage before it will be implemented for BAT determine and optimal control strategy $[18,36]$.

The market approach assumes an assessment of resource and energy potential of end product of faecal sludge. At the initial stage of development, it is necessary to conduct stakeholder analysis, as well as an analysis of the target market and, accordingly, a feasibility analysis of end products using within predetermined geographic boundaries (e.g., city or district) $[5,11,34]$.

Processing systems can only function sustainably if there is a demand for its end products (for example, biochar, biogas or energy) $[18,36]$. This process should be considerate as means of obtaining end product in order to reduce costs. This way the sanitation system would have financial support that would also reduce users costs and increase profits of collection and transportation companies. So, companies can sell faecal sludge to enterprises which will use it as a fuel (for example, energy-intensive processes such as cement production). In this case, 
the operator itself meets demand for the product, and company does not pay for the water discharge to local sewage, disposal sludge in drying bed or landfill, while they themselves are paid for the product $[18,19,27,36]$.

The sale of non-hazardous products of faecal sludge proceeding such as solid fuels, gas or fertilizer can partially cover treatment costs. These solutions require adaptation to local conditions, such as component composition of biological waste, seasonal availability, balance of supply and demand for a potential end product, and transportation costs to the place of application $[9,37]$.

Account must be taken of that there is no actual sales market for end products of faecal sludge processing in the Russian Federation. For this reason, the market for an alternative product should be considered, which could potentially vary when analysed. For example, if there is selecting composting technology, the end product is compost. In that way, production sources and market for compost obtained from other organic raw materials should be taken into account $[26,38]$.

Market size and market growth are critical points in assessing the viability of a faecal sludge processing product, but enterprise produced goods plays an equally important role. Its ability to compete in market conditions will depend on various internal and external factors that need to be analysed in detail in order to combine it with an analysis of market size and market growth to provide a once-smart and accurate picture of marketability [15,34].

As can be seen from the above blocks represent an integrated approach to the creation and regulation of a faecal waste management. For implementation such approach, a system of evaluation criteria is required in order to determine the end product and, accordingly, determine development direction of this industry in the geographical area where this system will operate.

Criteria are given below (Table 1). They combine all the steps for creating of faecal sludge management. These criteria should apply to predefined geographic boundaries, such as a region, city, or district.

Table 1. Criteria for sustainable faecal sludge management

\begin{tabular}{|l|l|}
\hline \multicolumn{1}{|c|}{ Criteria } & \multicolumn{1}{c|}{ Notes } \\
\hline Climatic conditions of area & Seasonal and climatic factors of the region \\
\hline Growth direction of area & Agriculture, industrial and cultural definition of area \\
\hline $\begin{array}{l}\text { Market participant } \\
\text { (producers) }\end{array}$ & $\begin{array}{l}\text { Analysis of producers who may be interested in faecal sludge } \\
\text { processing and production of end product }\end{array}$ \\
\hline $\begin{array}{l}\text { Market participant } \\
\text { (consumers) }\end{array}$ & $\begin{array}{l}\text { Analysis of potential consumers of end product (population, } \\
\text { enterprises, treatment facilities, etc.) }\end{array}$ \\
\hline $\begin{array}{l}\text { Best available technologies } \\
\text { of potential end products }\end{array}$ & $\begin{array}{l}\text { Consideration of criteria for each technology for generation priority } \\
\text { end product, pre-technological line, as well as environmental } \\
\text { protection technologies }\end{array}$ \\
\hline Market volume & $\begin{array}{l}\text { Market size assessment taking into account the correction factor } \\
\text { required in the absence of an existing product on the market }\end{array}$ \\
\hline Market growth & Assessment of sales growth for all sludge processing products \\
\hline Market attractiveness & Future market potential, which directly depends on demand \\
\hline
\end{tabular}

While assessing each of the criteria is considered separately in order to obtain more objective overall result.

\section{Conclusions}

The decisive factors of selection are flexibility of using this technology in different climate conditions, the high demand relative to other product, no additional pre-processing of raw materials, and also ecology-economical assessment of feasibility of using each method. 
The faecal sludge management in the Russian Federation is partially formed only at the local level: in "accumulation - collection - transportation - processing - utilization" chain there is no stage of resource using or energy potential recovery. Based on the developed principles of faecal sludge management and criteria for creating sustainable system, it is possible to create a favourable living environment for population, ensure the profitability of the management system and reduce the anthropogenic load in general.

\section{References}

1. On the state of rural areas in the Russian Federation in 2018 (Annual report on the results of monitoring: scientific ed.) (FGBNU "Rosinformagrotech", Moscow, 2020)

2. Citizen-Engagement at the forefront of the National Policy on Faecal Sludge and Septage Management (Ministry of Urban Development, Moscow, 2017)

3. Faecal sludge and septage management - An orientation module (Part A: learning notes) (NIUA, India, 2017)

4. S.O. Okoth, J.K. Ronoh, A. Dubois, D. Mbalo, Scaling up faecal sludge management in Kenya's urban areas (FSM Conference: Case Studies.Chennai, India, 2017)

5. K.C. Rao, E. Kvarnström, L. Di Mario, P. Drechsel, Business models for faecal sludge management (IWMI, Colombo, Sri Lanka, 2016)

6. P. Drechsel, M. Otoo, K.C. Rao, M.A. Hanjra, Resource recovery from waste: business models for energy, nutrient and water reuse in low-and middle-income countries, 4-15 (Routledge - Earthscan, Oxon, UK, 2018)

7. H. A. Qdais, F. Abdulla, A. Kurbatova, J. of Envir. Eng. and Sc., 14, 203-211 (2019)

8. M. Otoo, P. Drechsel, Resource recovery from waste: business models for energy, nutrient and water reuse in low- and middle-income countries (Routledge - Earthscan, Oxon, UK, 2018)

9. I. Blackett, P. Hawkins, FSM Innovation Case Studies - Case Studies on the Business, Policy and Technology of Faecal Sludge Management (second edition) (Bill \& Melinda Gates Foundation, USA, 2017)

10. Implementer's guide to lime stabilisation for septage management in the Philippines (USAID, Philippines, 2015)

11. I. Ross, R. Scott, A. Mujica, M. Smith, Faecal sludge management tools: data collection instruments (World Bank, Washington, DC, 2016)

12. I. Ross, R. Scott, A. Mujica, Z. White, M. Smith, Faecal sludge management: diagnostics for service delivery in urban areas - tools and guidelines (World Bank, Washington, DC, 2016)

13. Hand book on integarted wastewater and septage management for urban local bodies for Telangana (Commissioner \& Director of Municipal Administration, 2018)

14. H. Harada, L. Strande, S. Fujii, Challenges and Opportunities of Faecal Sludge Management for Global Sanitation (Towards Future Earth: Challenges and Progress of Global Environmental Studies. Kaisei Publishing, 2016)

15. E. Rollason, L.J. Bracken, R.J. Hardy, A.R.G. Large, J. of Env. Man., 228, 267-278 (2018)

16. L. Strande, D. Brdjanovic, M. Ronteltap, Faecal Sludge Management: Systems Approach for Implementation and Operation (IWA Publishing. UK, 2014)

17. P. Reymond, S. Renggli, C. Lüthi, Sust. Urbaniz., 30, 115-134 (2016) 
18. P.H. Dodane, M. Mbéguéré, O. Sow, L. Strande, Envir. Sci. \& Techn., 46, 3705-3711 (2012)

19. K. Foxon, C. Buckley, C. Brouckaert, B. Bakare, What happens when the pit is full? Developments in on-site faecal sludge management (FSM) (Water Research Commission, Durban, 2011)

20. A.N. Basamykina, M.D. Kharlamova, XX Intern. sc. and pract. conf. Actual. Problems of ecology and env. management, 81-89 (RUDN, Moscow, 2019)

21. S. Rothenberger, C. Zurbrügg, I. Enayetullah, A.H.M. Sinha, Decentralised composting for cities of low-and middle-income countries. A users' manual (Waste Concern, Dhaka, and Eawag, Dübendorf, 2006)

22. Federal Law of 24.06.1998 N89-FZ "On production and consumption waste"

23. Order of Rosprirodnadzor of 18.07.2014 N445 "On approval of the federal classification catalog of waste"

24. http://kod-fkko.ru/

25. Standard Operating Procedure for Faecal Sludge Management for Municipalities in Gujarat (CEPT University, 2015)

26. A. Basamykina, M. Kharlamova, S.Y. Mada, E3S Web of Conf., 169, 02008 (2020)

27. K. Ross, K. Abeysuriya, N. Mikhailovich, C. Mitchell, Governance for decentralized sanitation: Global Practice Scan (Institute for Sustainable Futures, ADRAS, 2014)

28. G. Edmund, Wagner, J. N. Lanoix, Excreta disposal for rural areas and small communitie. (WHO monograph series, no. 39, 1958)

29. WHO Water, Sanitation and Hygiene strategy 2018-2025 (WHO, Geneva, 2018)

30. S.O. Okoth, J.K. Ronoh, A. Dubois, D. Mbalo, FSM Conf.: Case Studies - Chennai, India, 54-66 (2017)

31. M. Cacanoski, Small-scale wastewater and faecal sludges treatment and management in low-income rural and peri-urban communities in developing countries (IRC International Water and Sanitation Centre, Delft, 2003)

32. Progress on Drinking Water, Sanitation and Hygiene: 2017 Update and SDG Baselines (WHO, UNICEF, Geneva, 2017)

33. C. Lüthi, A. Morel, E. Tilley, L. Ulrich, Community-led Urban Environmental Sanitation (CLUES), Complete Guidelines for Decision-makers with 30 Tools (Dübendorf, 2011)

34. I. Zabaleta, H. Mendez, C. Zurbrügg, Sandec: Dep. of San., Water and Solid Waste for Devel., 19, 5 (2018)

35. https://investmoscow.ru/business/public-private-partnership

36. S. Diener, M.A. Gallardo, C.R. Lohri, Y. Vögeli, C. Zurbrügg, Anaerobic digestion of biowaste in developing countries. Practical information and case studies report. (Eawag, Sandec, 2014)

37. L. Strande, Water21, 16-18 (2014)

38. L. Schoebitz, N. Andriessen, S. Bollier, M. Bassan, L., Strande Market driven approach for selection of faecal sludge treatment products (Eawag, Dübendorf, 2016) 